\title{
Expression and Localization of Fas Ligand and Fas During Atresia in Porcine Ovarian Follicles
}

\author{
Naoko INOUE'), Akihisa MAEDA ${ }^{2)}$, Fuko MATSUDA-MINEHATA ${ }^{2)}$, \\ Katsuhiro FUKUTA ${ }^{1)}$ and Noboru MANABE ${ }^{2)}$
}

\author{
1)Laboratory of Animal Morphology and Function, Graduate School of Bioagricultural \\ Sciences, Nagoya University, Nagoya 464-8601 and ${ }^{2)}$ Research Unit for Animal Life Sciences, \\ Animal Resource Science Center, The University of Tokyo, Ibaraki-Kasama 319-0206, Japan
}

\begin{abstract}
To reveal the mechanisms regulating the selective atresia of follicles in porcine ovaries, we examined the changes in the mRNA and protein levels of cell-death ligand, Fas/APO-1/CD95 ligand (FasL), and its receptor, Fas / APO-1/CD95 (Fas), and the localization of the proteins in granulosa cells during follicular atresia using the reverse transcription-polymerase chain reaction (RT-PCR), Western blotting, and immunohistochemical techniques, respectively. Trace levels of FasL mRNA and protein were detected in the granulosa cells of healthy follicles; however, weak levels were detected in those of early atretic follicles, and the levels increased during atresia. Trace/weak levels of Fas mRNA and protein were detected in the granulosa cells of healthy follicles. Fas protein was located in the cytoplasmic area, not in cell membrane area, indicating that it has no activity in regard to inducing apoptosis. When apoptosis commences in granulosa cells, Fas moves from the cytoplasmic to cell membrane area. FasL and Fas mRNAs and proteins in granulosa cells were upregulated during follicular atresia. The FasL and Fas system may play a crucial role in the regulation of apoptosis in granulosa cells during selective follicular atresia in porcine ovaries.
\end{abstract}

Key words: Apoptosis, Fas/APO-1/CD95 (Fas), Fas/APO-1/CD95 ligand (FasL), Follicular atresia, Granulosa cell, Porcine ovary

(J. Reprod. Dev. 52: 723-730, 2006)

$\mathrm{n}$ mammalian ovaries, more than $99 \%$ of

follicles undergo a degenerative process known as atresia [1-7]. Recent studies suggest that apoptosis of follicular granulosa cells plays a crucial role in the initiation of this process. We have previously investigated the molecular mechanisms regulating follicular atresia in porcine ovaries [8]. Our findings indicate that apoptosis of granulosa cells is involved in follicular selection [810]. Studies on the signal for apoptosis, which is transduced from extra- to intracellular parts, have focused on the pathway mediated by death ligand

Accepted for publication: July 10, 2006

Published online: August 23, 2006

Correspondence: N. Manabe (amanabe@mail.ecc.u-tokyo.ac.jp) and its receptor system, such as the tumor necrosis factor (TNF)- $\alpha$ and TNF receptor (TNFR) system [11] and TNF-related apoptosis-inducing ligand (TRAIL) and receptor system [12]. In porcine granulosa cells, TNF- $\alpha$ acts as a survival factor because TNFR-2, which induces a survival signal, was expressed, but not TNFR-1 [11]. In TRAIL and its receptor system, death receptor (DR)-4, DR-5, and decoy receptor (DcR)-1 were detected [12]. Moreover, DcR-1 was expressed in the porcine granulosa cells of healthy follicles but not in those of atretic follicles. In atretic follicles, abundant levels of TRAIL, DR-4, and DR-5 were detected in granulosa cells. TRAIL and its receptors are considered to be involved in apoptosis signal 
induction [12]. Fas (also called Apo-1 or CD95) is also an apoptosis-inducing receptor, and its ligand, Fas ligand (FasL; also called Apo-1 ligand or CD95 ligand), which is a type II membrane protein, induces apoptosis by binding with Fas. FasL and Fas are expressed in the ovaries of humans, mice, rats, cows, and hens [13-16], but their expression in porcine ovaries has not been confirmed. In porcine, bovine, and murine ovaries, species-specific differences have been noted in apoptotic cell localization in granulosa and theca interna cells during follicular atresia [17]; thus, the regulatory mechanisms of granulosa cell apoptosis are considered to differ among species. Abnormal ovarian follicular development and increased numbers of secondary follicles, but not tertiary follicles, has been noted in MRL-lpr/lpr mutant mice, which lack functional Fas [18]. In murine ovaries, oocytes promote the proliferation of granulosa cells during follicular development from preantral (primary and secondary) and antral (tertiary) follicles [19], and Fas is detected in the oocytes of atretic follicles but not in those of healthy follicles [20]. However, the precise roles of the FasL and Fas system in follicular selection in porcine ovaries have not been elucidated.

In the present study, to confirm the roles of the FasL and Fas system in the regulation of selective atresia of ovarian follicles in porcine ovaries, we examined the changes in the mRNA and protein levels of FasL and Fas and in the localization of the proteins in granulosa cells during follicular atresia using reverse transcription-polymerase chain reaction (RT-PCR), Western immunoblotting, and immunohistochemical staining, respectively.

\section{Materials and Methods}

\section{Preparation of granulosa cells}

The ovaries of mature sows (weighing more than $120 \mathrm{~kg}$ ) were obtained from a local slaughterhouse for use in this study. As described previously [12], each tertiary follicle, approximately $3 \mathrm{~mm}$ in diameter, was dissected from the ovaries under a surgical dissecting microscope (SZ40; Olympus, Tokyo, Japan) and was classified as morphologically healthy or atretic, the latter type being further subdivided into early and progressed atretic. Follicular fluid from each follicle was collected using a 1-ml syringe, separated by centrifugation at $3,000 \mathrm{~g}$ for $10 \mathrm{~min}$ at $4 \mathrm{C}$, frozen, and kept at $-80 \mathrm{C}$ until to use. After biochemical analyses (RT-PCR and Western blot) were performed, the $17 \beta$-estradiol (E2) and progesterone (P4) levels were retrospectively measured using [ ${ }^{125}$ I]-RIA kits (bioMérieux, Marcyl’Etolle, France) to confirm the classification of the follicles. Follicles with a P4/E2 ratio of less than 15 were classified as healthy according to previous findings $[8,9]$. Each follicle was opened using fine \#5 watchmaker fine forceps, and the granulosa layers and oocytecumulus complexes were removed. The granulosa layers of healthy follicles and the granulosa cells of atretic follicles were used for biochemical analyses.

\section{RT-PCR analysis}

As described previously [12], for RT-PCR analysis, mRNA was extracted from each granulosa cell sample using a QuickPrep Micro mRNA Purification Kit (Amersham Pharmacia Biotech, Piscataway, NJ, USA) and then reverse-transcribed using You-Prime First-Strand Beads (Amersham Pharmacia Biotech) to synthesize cDNA. The primers for amplification of partial cDNA sequences of porcine FasL (GeneBank accession number: AY033634), Fas (AJ001202), and glyceraldehyde-3-phosphate dehydrogenase (GAPDH; AF017079, used as an intrinsic control) were as follows: for FasL, forward 5'-CTCAA GATCC ATCCC TCTGG-3' and reverse $5^{\prime}$-TCATC TTTCC CTCCA TCAGC-3' for Fas, forward 5'TTGAG AATTG CACAC CAACC- $3^{\prime}$ and reverse 5'CGATA CCATT CTTCC GAACG-3'; and for GAPDH, forward 5'-GATGG TGAAG GTCGG AGTG-3' and reverse 5'-CGAAG TTGTC ATGGA TGACC-3'. The expected PCR product sizes of FasL, Fas, and GAPDH were 227, 300, and 500 bp, respectively. PCR amplification was performed as follows: Platinum Taq DNA Polymerase (10,000 U/ $\mathrm{ml}$; Gibco BRL, Grand Island, NY, USA) was added to the cDNA mixture (each cDNA sample was mixed with PCR mix containing $1 \times$ PCR buffer, 0.1 $\mathrm{mM}$ dNTP mixture, $1.5 \mathrm{mM} \mathrm{MgCl}$, and $0.5 \mu \mathrm{M}$ of each primer) and denatured. The mixture was subjected to PCR in a thermal cycler (GeneAmp PCR Systems 2400; PE Applied Biosystems, Foster City, CA, USA). The hot-start PCR cycles for FasL, Fas, and GAPDH were as follows: $96 \mathrm{C}$ for $4 \mathrm{~min}$; 35 cycles of $94 \mathrm{C}$ for $1 \mathrm{~min}, 58 \mathrm{C}$ for $1 \mathrm{~min}$, and $72 \mathrm{C}$ for $1 \mathrm{~min}$; and a final extension period at $72 \mathrm{C}$ for 10 min. PCR products were electrophoresed in $2 \%$ 
$(\mathrm{w} / \mathrm{v})$ agarose gels (Sigma-Aldrich Chemicals, St. Louis, MO, USA) and stained with ethidium bromide (Wako Pure Chemical, Osaka, Japan). Ready-Load 100-bp DNA Ladder (Gibco) was used as a molecular weight marker for electrophoresis. After electrophoresis, the stained gels were recorded with a digital fluorescence recorder (LAS1000; Fuji Film, Tokyo, Japan), and each mRNA expression level, the fluorescence intensity of each band of PCR product, was quantified using the Image Gauge software (Fuji Film) on a Macintosh computer. The relative abundance of specific mRNA was normalized to the relative abundance of GAPDH mRNA. Then the percent increase against each healthy control was calculated. To confirm the expression of the porcine FasL and Fas mRNAs, the DNA sequence of the PCR product was determined using an automatic DNA sequencer (ABI Prism 310; PE Applied Biosystems). All the above procedures were performed according to the manufacturer's instructions.

\section{Western immunoblot analysis}

As previously reported [12], for Western immunoblotting, a protein fraction (50 $\mu \mathrm{g} /$ lane) was prepared from the lysate of granulosa cells, which were obtained from healthy or atretic follicles, separated by $10-20 \%$ gradient sodium dodecyl sulfate-polyacrylamide gel electrophoresis (SDS-PAGE; Wako), and then transferred onto nitrocellulose membranes (Hybond-C, Amersham Pharmacia). The membranes were stained with a $0.2 \%(\mathrm{w} / \mathrm{v})$ Ponceau S solution (Serva Electrophoresis, Heidelberg, Germany), immersed in blocking solution [20 mM Tris- $\mathrm{HCl}(\mathrm{pH} 7.6), 137$ $\mathrm{mM} \mathrm{NaCl}$, and $0.1 \%(\mathrm{v} / \mathrm{v})$ Tween-20 (Sigma) containing $5 \%(\mathrm{w} / \mathrm{v})$ skim milk] for $30 \mathrm{~min}$, and incubated with each primary antibody [mouse antiporcine FasL monoclonal antibody (diluted 1:500 with blocking solution; Transduction Laboratories, Lexington, KY, USA) and mouse anti-porcine Fas monoclonal antibody (diluted 1:100 with blocking solution, ZB4 clone; MBL, Nagoya, Japan)] at 4 C for $18 \mathrm{~h}$. After a wash with blocking solution, they were incubated with horseradish peroxidase (HRP)-conjugated goat anti-mouse IgG antibody (diluted 1:5,000 with blocking solution; Amersham Pharmacia) for $1 \mathrm{~h}$ at $25 \mathrm{C}$, and then chemiluminescence was visualized using an ECL system (Amersham Pharmacia) according to the manufacturer's protocol. The chemiluminescence was recorded with a digital fluorescence recorder. Each protein expression level, the chemiluminescence intensity of each protein band, was quantified using the Image Gauge software on a Macintosh computer, and then the percent increase against each healthy control was calculated.

\section{Immunohistochemistry for FasL and Fas}

Frozen sections were used for observation of the localization of FasL. Briefly, ovaries obtained from mature sows were cut (less than $1 \times 1 \times 1 \mathrm{~cm}$ ) and rapidly frozen at a local slaughterhouse. Serial sections $5 \mu \mathrm{m}$ thick were mounted onto glass slides precoated with 3-aminopropyltriethoxysilane (Silan; Sigma) and fixed in cold acetone $(-80 \mathrm{C})$ for $10 \mathrm{~min}$. After being washed with phosphatebuffered saline (PBS; pH 7.4), the slides were incubated with mouse anti-porcine FasL monoclonal antibody (diluted 1:100 with PBS) for $18 \mathrm{~h}$ at $4 \mathrm{C}$, washed with PBS, and then incubated with mixed solution [ $25 \mu \mathrm{g} / \mathrm{ml}$ of Alexa Fluor 488conjugated goat anti-mouse IgG (Molecular Probes, Poortgebouw, Netherlands) and $20 \mu \mathrm{g} / \mathrm{ml}$ of propidium iodide (PI: Sigma)] for $90 \mathrm{~min}$ at room temperature (22-25 C). The sections were washed 3 times with PBS, mounted with glycerol, and then examined with a confocal laser scanning microscope (Fluoview FV300; Olympus).

Paraffin sections were used for observation of the localization of Fas. Briefly, ovaries were fixed in $10 \%(\mathrm{v} / \mathrm{v})$ phosphate-buffered formalin $(\mathrm{pH} 7.4)$, dehydrated through a graded ethanol series, and embedded in Histosec-paraffin (Merck, Darmstadt, Germany). Sections $3 \mu \mathrm{m}$ thick were mounted onto glass slides precoated with silan, deparaffinized, rehydrated, and then washed well with TBST solution [20 mM Tris- $\mathrm{HCl}(\mathrm{pH} 7.6), 137 \mathrm{mM} \mathrm{NaCl}$, and $0.1 \%(\mathrm{v} / \mathrm{v})$ Tween-20]. The slides were pretreated with $0.1 \%(\mathrm{v} / \mathrm{v}) \mathrm{H}_{2} \mathrm{O}_{2}$ in methanol for 5 min, washed with TBST, and then incubated with primary antibody [mouse anti-porcine Fas monoclonal antibody (diluted 1:100 with TBST; Sigma)] for $18 \mathrm{~h}$ at $4 \mathrm{C}$. After a thorough wash with TBST, they were incubated with biotinylated antimouse IgG antibody (Dako, Glostrup, Denmark) for $15 \mathrm{~min}$ at room temperature, washed well with TBST, and post-treated with streptavidinperoxidase complex (Envision immunostaining system; Dako) for $15 \mathrm{~min}$ at room temperature. After washing again with TBST, the slides were 
incubated with amplification reagent (Envision immunostaining system) for $10 \mathrm{~min}$ at room temperature, washed with TBST, and then treated with substrate-chromogen solution (Envision immunostaining system) for $1 \mathrm{~min}$. The slides were then rinsed with distilled water, counterstained with methyl green, dehydrated, mounted with Entellan (Merck), and examined by light microscopy (BX-51, Olympus). In each experimental run, adjacent sections incubated without each primary antibody or without any antibodies were prepared as negative controls.

\section{Statistical analysis}

All experiments involving the isolation of follicles were repeated with separate groups (nine sows/group) for independent observation. ANOVA with Fisher's least significant difference test comparison for biochemical data and Wilcoxon's signed-rank tests for histological estimation were carried out using the StatView-4.5 program (Abacus Concepts, Berkely, CA, USA) on a Macintosh computer. Differences of $\mathrm{P}<0.05$ were considered significant.

\section{Results}

Changes in the expression of FasL and Fas mRNAs in granulosa cells

The RT-PCR products detected in the present study were confirmed to be porcine FasL and Fas by sequencing the cDNA. The cDNA sequence of FasL amplified by RT-PCR was 5'-CTCAA GATCC ATCCC TCTGG AATGG GAAGA CACCT ATGGA ATTGC CTTGG TCTCT GGGGT GAAGT ATATG AAgGG CAGCC TTGTG ATCAA TGACA CTGGG CTGTA TTTTG TGTAT TCCAA AGTGT ACTTC CGGGG TCAGT ACTGC AACAA CCAGC CCCTG AGTCA CAAGG TATAC ACAAG GAACT CTAGG TATCC CCAGG ACCTG GTGCT GATGG AGGGA AAGAT GA-3' (227 bp). That of Fas amplified by RT-PCR was 5'TTGAG AATTG CACAC CAACC AGCAA CACCA AATGC AGAGA AGTGT TCCAA TCTGC AGGAT CCAGA TCTAA CCTAC ACTGG TTATG GGCCC TCCTG ATCCT CATTC CCGTA CCTGC ACTGG TATAC AgGGA GGTGA AAAGA CGGTG CAGAA GAAAA GAGAA TGGTT ACCAG AAACC TATCA CCTCA AATGC TGAAG AGGTG CCAAT GATAA AAGAC
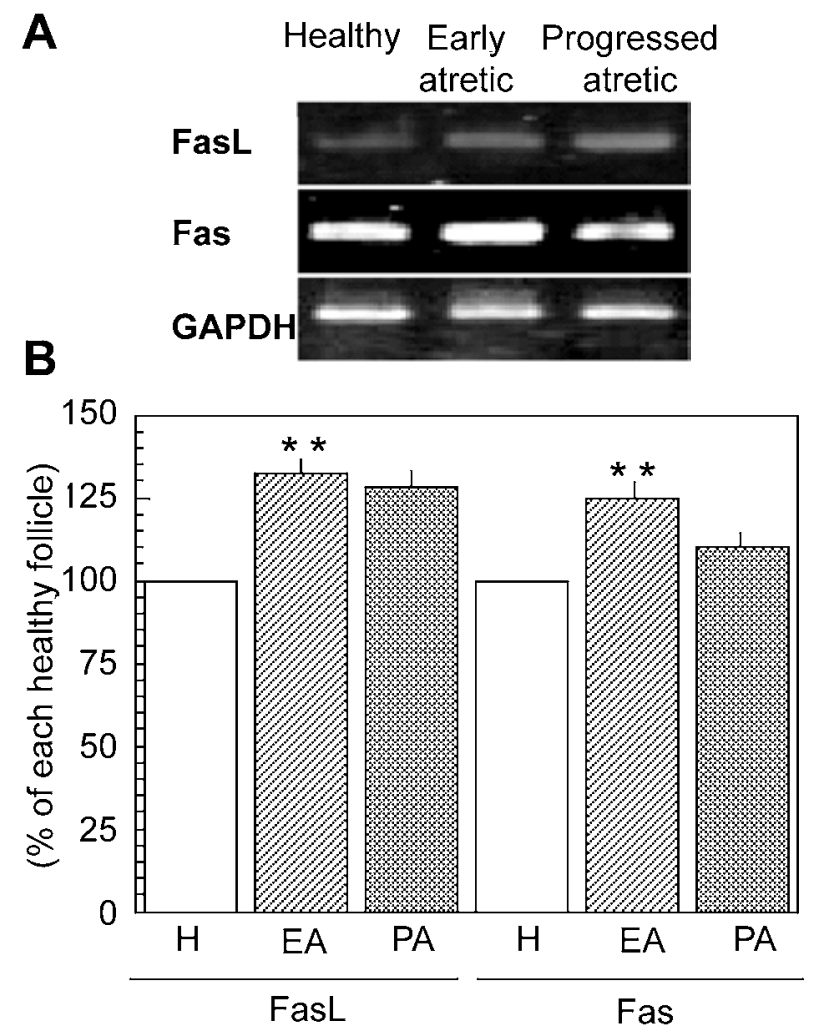

Fig. 1. Changes in the expression levels of FasL and Fas mRNAs in the granulosa cells of healthy $(\mathrm{H})$, early atretic (EA), and progressed atretic (PA) follicles were assessed by RT-PCR. As an intrinsic control, the GAPDH mRNA level was measured in the same samples. Representative photographs of the electrophoresis are shown in A. FasL and Fas mRNA levels were normalized to the GAPDH mRNA level, and then the percentage of increase against healthy follicles was calculated (B). Values represent means + $\mathrm{SE}$ from three independent experiments. Increases in both the FasL and Fas mRNA expressions were observed during follicular atresia. ${ }^{* *}: \mathrm{P}<0.01$ vs healthy follicle.

GTTGA CTTGG GTAAA TATAT CACCC GTATT GCTGA ACAGA TGAAA ATAAC TGAAG TTAAA GATTT CGTTC GGAAG AATGG TATCG-3' (300 bp).

FasL, Fas, and GAPDH mRNAs in isolated granulosa cells of healthy, early atretic, and progressed atretic follicles were detected by RTPCR (Fig. 1A). The fluorescence intensity was quantified using an automatic image-analyzer, and then the relative abundance of specific mRNA was normalized to the relative abundance of GAPDH mRNA. The percent increase against each healthy control was calculated. Both the FasL and Fas 
A

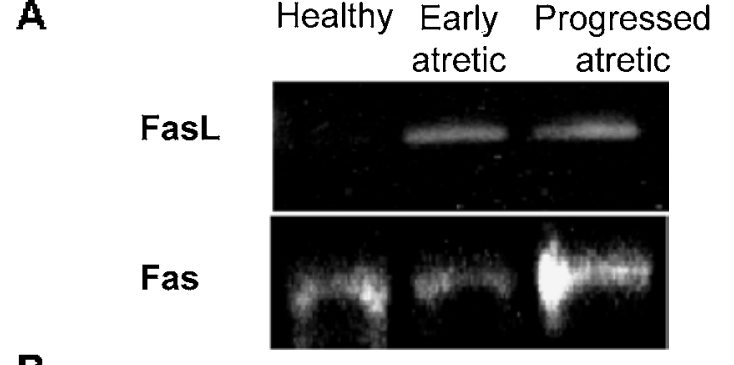

B

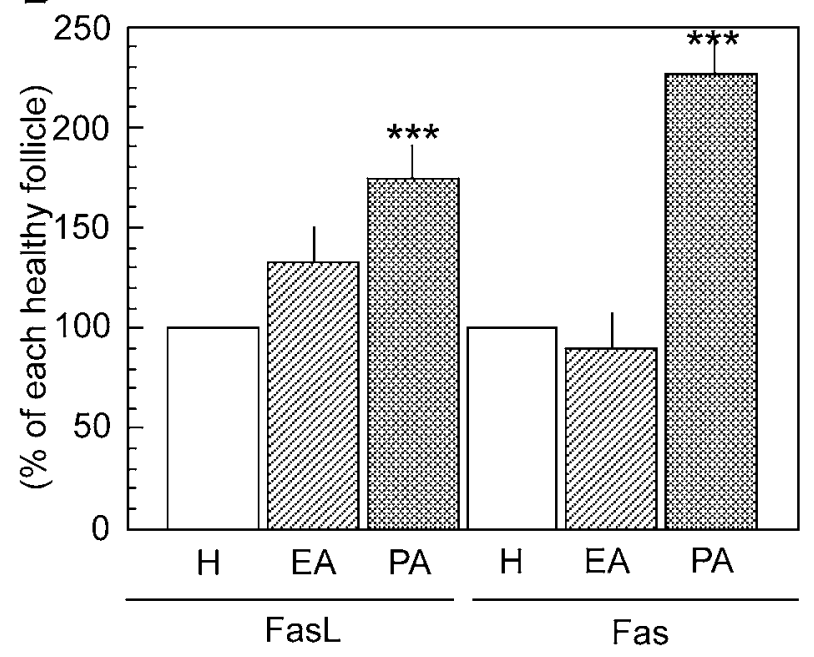

Fig. 2. Changes in the expression levels of FasL and Fas proteins in the granulosa cells of healthy $(\mathrm{H})$, early atretic (EA), and progressed atretic (PA) follicles were examined by Western blotting. Representative photographs of chemiluminescence-Western blotting for FasL and Fas are shown in A. The FasL and Fas protein levels are summarized in B. The FasL and Fas protein expression levels in granulosa cells increased during follicular atresia. Values represent means + SE from three independent experiments. ${ }^{* * *}: \mathrm{P}<0.001$ vs healthy follicle.

mRNA expression levels increased during follicular atresia $(\mathrm{P}<0.05)$ (Fig. 1B). Higher expression levels of FasL mRNA were noted in granulosa cells of early atretic and progressed atretic follicles (FasL mRNA/GAPDH mRNA; 32.1 and $28.4 \%$ increases, respectively) than in those of healthy follicles. Fas mRNA levels were increased during follicular atresia, and trace levels were seen in the granulosa cells of healthy follicles (Fas mRNA/GAPDH mRNA; 25.1 and 10.3\% increases, respectively).
Changes in the expression of FasL and Fas proteins in granulosa cells

Trace levels of FasL protein $(37 \mathrm{kDa})$ were detected in the granulosa cells of healthy follicles (Fig. 2A). The chemiluminescence intensity quantified using an automatic image analyzer showed that the FasL protein levels increased during follicular atresia $(\mathrm{P}<0.01)$ (Fig. 2B). Trace/ weak levels of Fas protein $(48 \mathrm{kDa})$ in healthy follicles were detected, and the chemiluminescence intensity also increased during follicular atresia.

\section{Changes in the localization of FasL and Fas proteins in follicular tissues}

No positive immunostaining for FasL was observed in the granulosa cells of healthy follicles, and positive immunostaining for FasL (Fig. 3A and B) was observed in granulosa cells from the inner granulosa layers of atretic follicles. However, no positive staining was detected in the cells of the theca interna or externa layers of healthy or atretic follicles. Weak staining for Fas was seen in the granulosa cells of healthy follicles, and positive staining for Fas was seen in scattered cells of the granulosa layers of atretic follicles (Fig. 3D). The intensity of both FasL and Fas-staining increased during follicular atresia.

\section{Discussion}

In mammalian ovaries, follicular atresia is involved in granulosa cell apoptosis, a physiological cell death named by Kerr et al. [7]. Researchers have reported that more than $99 \%$ of ovarian follicles fail and that only a few follicles reach ovulation [21]. Granulosa cell apoptosis in ovarian follicles takes part in the selection of ovarian follicles [22-31]. We have previously demonstrated that the death ligand/receptor system (TNF $\alpha / \mathrm{TNFR}$, TRAIL/TRAIL receptors) is involved in follicular selection [11, 12, 29, 30]. FasL and Fas expression have been examined in various animals, such as humans, mice, rats, cows, and hens [13-16]. FasL and Fas mRNA and protein expression and localization show species specificity. The present study was conducted to confirm the role of the FasL and Fas system in granulosa cell apoptosis in porcine ovaries.

In the present examination, we demonstrated that Fas mRNA and protein were present in the 

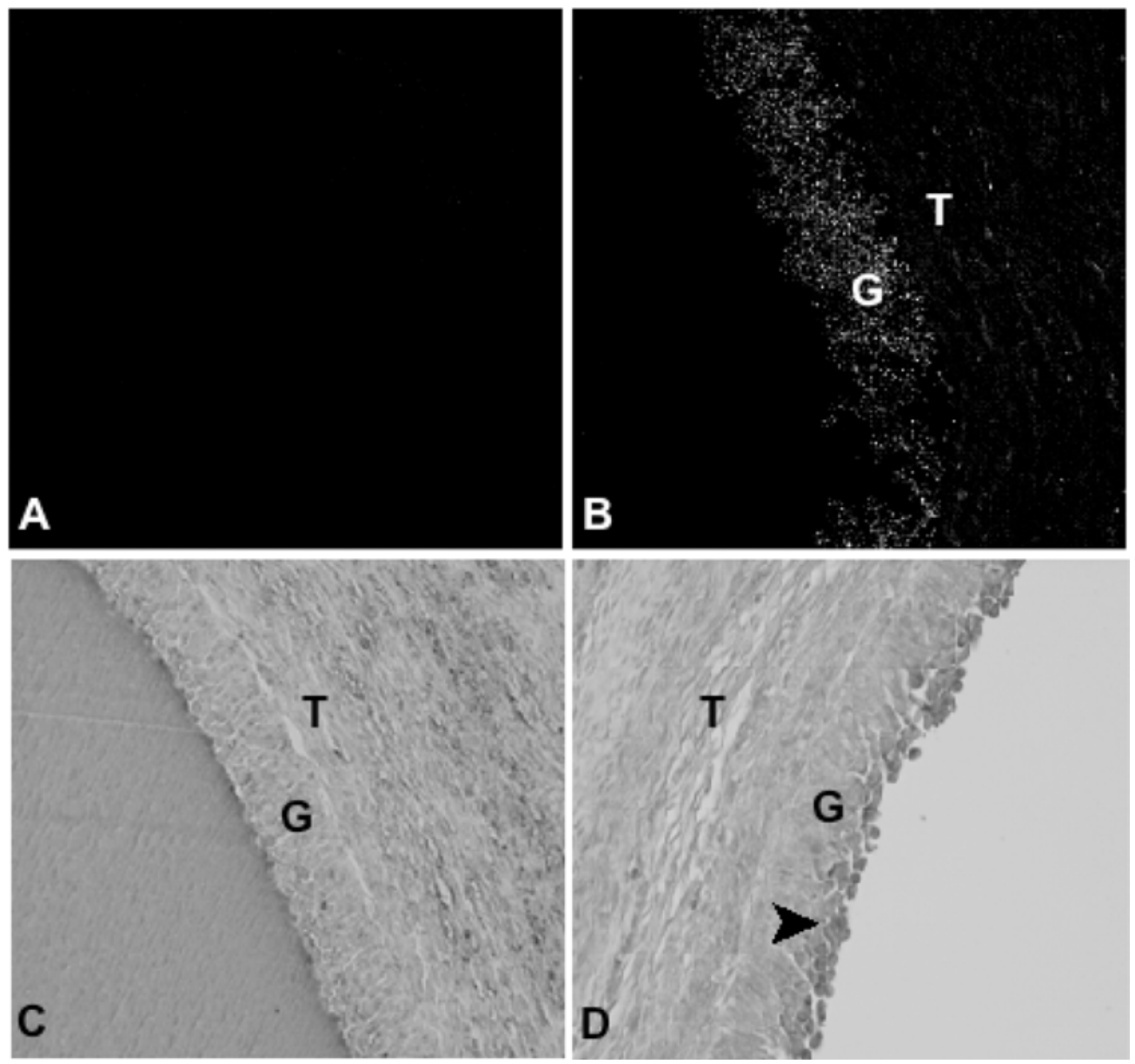

Fig. 3. The localization of FasL and Fas proteins was demonstrated by immunohistochemistry. Pig ovarian sections from healthy (A and C) and progressed atretic (B and D) follicles were immunohistochemically stained for FasL (A and B) and Fas (C and D). During follicular atresia, increases were observed in the staining for the FasL and Fas proteins. Magnification: $\times 200$.

healthy, early atretic, and progressed atretic follicles of porcine ovaries; however, FasL mRNA expression increased during follicular degeneration. Notably, an extremely low level of FasL protein was detected in healthy follicles. A low level of Fas protein was found in healthy follicles. Fas protein was located in the cytoplasmic area but not in cell membrane area. We presume that the Fas in the granulosa cells of healthy follicles is not functional or able to induce apoptosis. In atretic follicles of bovine ovaries, FasL protein has been localized in the theca layers, and Fas has been detected in the granulosa layer [15]. In rat ovaries, Fas was scattered in the granulosa cells of early and progressed atretic follicles, and no FasL was observed in the granulosa cells of healthy antral follicles [14]. Our previous reports have shown that granulosa cells located on the antral side trigger apoptosis and that cell death extends toward the basement membrane side. In the present study, we detected Fas protein in cells located on the antral side of the granulosa layer of very early atretic follicles, similar to the localization of the apoptotic cells in atretic follicles of the porcine ovaries. Interestingly, we had no positive immunohistochemical staining for FasL or Fas in the theca layers of the porcine ovaries. In the bovine ovary, however, FasL and Fas signals are more intense in the theca layers during follicular atresia [15]. Our previous report showed that apoptotic cells are located in granulosa cells from the early to progressed stages of follicular atresia in porcine 
ovaries, but not in the cells of the internal or external theca layers [23, 24]. Moreover, this recent research demonstrates that activated caspase-3, which is a key proteolytic enzyme and downstream part of the FasL-Fas-dependent apoptotic signaling pathway system, is located in granulosa cells in the early and progressed atretic follicles of porcine ovaries. In murine ovaries, FasL protein was located in granulosa cells and Fas protein was expressed in oocytes. Thus, apoptosis in oocytes may be induced by granulosa cells [20]. On the other hand, in rat ovaries, FasL was located in oocytes, and Fas was detected in granulosa cells [14]. However, in porcine ovaries, no expression of Fas was detected in oocytes. Moreover, we previously demonstrated that no apoptosis was induced in oocytes or the cumulus cells surrounding the oocytes in early atretic follicles and that apoptosis was induced in most of the cumulus cells, but not in the oocytes, of progressed atretic follicles, indicating that apoptosis was not induced in the oocytes [17]. In terms of the regulatory mechanism of apoptosis, the relationship between oocytes and granulosa cells, including cumulus cells, may be species-specific and more detailed investigations are necessary.

In summary, in the granulosa cells of porcine ovarian follicles, FasL acts as a trigger to induce apoptosis by binding to the extracellular domain of
Fas [31]. In the granulosa cells of healthy follicles, no FasL protein was expressed, and the trace level of Fas protein, located in the cytoplasmic area but not in the cell membrane area, had no activity in regard to inducing apoptosis. When apoptosis commences in granulosa cells, the expression of FasL and Fas is upregulated, and Fas moves from the cytoplasmic to cell membrane area. Thus, the FasL and Fas system may play crucial roles in the regulation of selective granulosa cell apoptosis in porcine ovaries during follicular atresia and may act as a regulator of apoptosis in granulosa cells.

\section{Acknowledgements}

This work was supported by a Grant-in Aid for Young Scientist (B) (17780216) to N. I. and Exploratory Research (18658105) to N. M. from the Ministry of Education, Culture, Sports, Science and Technology of Japan, and Grants-in-Aid for Creative Scientific Research (13GS0008), Scientific Research (B) (18380164), (S) (16108003 and 18108004) to N. M. from the Japan Society for the Promotion of Science. We are grateful to Dr. Takashi Miyano (Kobe University, Kobe, Japan) for his advice on the determination of healthy and atretic follicles and preparation of granulosa cells.

\section{References}

1. Ellis RE, Yuan JY, Horvitz HR. Mechanisms and functions of cell death. Annu Rev Cell Biol 1991; 7: 663-698.

2. Hsu SY, Hsueh AJW. Hormonal regulation of apoptosis. An ovarian perspective. Trends Endocrinol Metab 1997; 8: 207-213.

3. Utz PJ, Anderson P. Life and death decisions: regulation of apoptosis by proteolysis of signaling molecules. Cell Death Differ 2000; 7: 589-602.

4. Zeleznik AJ, Ihrig LL, Bassett SG. Developmental expression of $\mathrm{Ca}^{++} / \mathrm{Mg}^{++}$-dependent endonuclease activity in rat granulosa and luteal cells. Endocrinology 1989; 125: 2218-2220.

5. Hughes FM Jr, Gorospe WC. Biochemical identification of apoptosis (programmed cell death) in granulosa cell: evidence for a potential mechanism underlying follicular atresia. Endocrinology 1991; 129: 2415-2422.

6. Tilly JL, Kowalski KI, Johnson AL, Hsueh AJW. Involvement of apoptosis in ovarian follicular atresia and postovulatory regression. Endocrinology 1991; 129: 2799-2801.

7. Kerr JFR, Wyllie AH, Currie AR. Apoptosis: a basic biological phenomenon with wide ranging implication in tissue kinetics. Br J Cancer 1972; 26: 239-257.

8. Manabe N, Kimura Y, Myoumoto A, Matsushita $H$, Tajima C, Sugimoto M, Miyamoto $H$. Role of granulosa cell apoptosis in ovarian follicle atresia. In: Yamada T, Hashimoto Y (eds.), Apoptosis: Its Roles and Mechanism. Tokyo: Jpn Acad Soc Book Cent; 1998: 97-111.

9. Manabe N, Myoumoto A, Kimura Y, Imai Y, Sugimoto M, Sakamaki K, Okamura Y, Fukumoto M, Miyamoto H. Regulatory mechanisms of granulosa cell apoptosis in porcine ovarian follicle atresia. In: Miyamoto $\mathrm{H}$, Manabe $\mathrm{N}$ (eds.), Reproductive Biology Update. Kyoto: Shoukado Pub Co; 1998: 23-35.

10. Manabe N, Kimura Y, Uchio K, Tajima C, 
Matsushita H, Nakayama M, Sugimoto $M$, Miyamoto H. Regulatory mechanisms of granulosa cell apoptosis in ovarian follicle atresia. In: Ikura K, Nagao M, Masuda S, Sasaki R (eds.), Animal Cell Technology. Dordrecht: Kluwer Academic Pub; 1999: 334-343.

11. Nakayama $\mathbf{M}$, Manabe $\mathbf{N}$, Inoue $\mathbf{N}$, Matsui $\mathbf{T}$, Miyamoto $\mathbf{H}$. Changes in the expression of tumor necrosis factor (TNF) $\alpha$, TNF $\alpha$ receptor (TNFR) 2 and TNFR-associated factor 2 in granulosa cells during atresia in pig ovaries. Biol Reprod 2003; 68: 530-535.

12. Inoue $\mathbf{N}$, Manabe $\mathbf{N}$, Matsui $T$, Maeda $A$, Nakagawa S, Wada S, Miyamoto H. Roles of tumor necrosis factor-related apoptosis-inducing ligand signaling pathway in granulosa cell apoptosis during atresia in pig ovaries. J Reprod Dev 2003; 49: 313-321

13. Quirk SM, Cowan RG, Josh SG, Henrikson KP. Fas-mediated apoptosis in human granulosa/luteal cells. Biol Reprod 1995; 52: 279-287.

14. Kim JM, Yoon YD, Tsang BK. Involvement of the Fas/FasL system in p53-mediated granulosa cell apoptosis during follicular development and atresia. Endocrinology 1999; 140: 2307-2317.

15. Vickers SL, Cowan RG, Harman RM, Porter DA, Quirk SM. Expression and activity of the Fas in bovine ovarian follicle cells. Biol Reprod 2000; 62: 5461.

16. Bridgham JT, Johnson AL. Expression and regulation of Fas and tumor necrosis factor receptor type I in hen granulosa cells. Biol Reprod 2001; 65: 733-739.

17. Nakayama M, Manabe N, Nishihara S, Miyamoto H. Species specific differences in apoptotic cell localization in granulosa and theca interna cells during follicular atresia in porcine and bovine ovaries. J Reprod Dev 2000; 46: 147-156.

18. Sakamaki K, Yoshida H, Nishimura Y, Nishikawa S, Manabe N, Yonehara S. Involvement of Fas antigen in ovarian follicular atresia and luteolysis. Mol Reprod Dev 1997; 47: 11-18.

19. Vanderhyden BC, Telfer EE, Eppig JJ. Mouse oocytes promote proliferation of granulosa cells from preantral and antral follicles in vitro. Biol Reprod 1992; 46: 1196-1204.

20. Dharma SJ, Kelkar RL, Nandedkar TD. Fas and Fas ligand protein and mRNA in normal and atretic mouse ovarian follicles. Reproduction 2003; 126: 783 789.

21. Tilly JL. Apoptosis and ovarian function. Rev Reprod 1996; 1: 162-172.

22. Manabe N, Inoue N, Miyano T, Sakamaki K, Sugimoto $\mathbf{M}$, Miyamoto $\mathbf{H}$. Ovarian follicle selection in mammalian regulatory mechanisms of granulosa cell apoptosis during follicular atresia. In: Leung PK, Adashi E (eds.), The Ovary 2nd edition. Amsterdam: Academic Press Elsevier Science; 2003: 369-385.

23. Manabe N, Imai Y, Ohno H, Takahagi Y, Sugimoto $\mathbf{M}$, Miyamoto $\mathbf{H}$. Apoptosis occurs in granulosa cells but not cumulus cells in the atretic antral follicles in the pig ovaries. Experientia 1996; 52: 647651.

24. Manabe N, Imai $\mathbf{Y}$, Myoumoto A, Kimura $\mathbf{Y}$, Sugimoto M, Okamura Y, Fukumoto M, Sakamaki $\mathbf{K}$, Miyamoto H. Apoptosis occurs in granulosa cells but not cumulus cells in the atretic Graafian follicles in multiparous pig ovaries. Acta Histochem Cytochem 1997; 30: 85-92.

25. Sugimoto M, Manabe N, Kimura $\mathbf{Y}$, Myomoto A, Imai $\mathbf{Y}$, Ohno $\mathbf{H}$, Miyamoto $\mathbf{H}$. Ultrastructural changes in granulosa cells in porcine antral follicles undergoing atresia indicate apoptotic cell death. J Reprod Dev 1998; 44: 7-14.

26. Manabe N, Myomoto A, Tajima C, Fukumoto M, Nakayama M, Uchio K, Yamaguchi M, Miyamoto H. Immunochemical characteristics of a novel cell death receptor and a decoy receptor on granulosa cells of porcine ovarian follicles. Cytotechnology 2000; 33: 189-201.

27. Kimura $\mathbf{Y}$, Manabe N, Nishihara S, Matsushita $\mathbf{H}$, Tajima C, Wada S, Miyamoto H. Up-regulation of the $\alpha 2,6$-sialyltransferase messenger ribonucleic acid increases glycoconjugates containing $\alpha 2,6-$ linked sialic acid residues in granulosa cells during follicular atresia of porcine ovaries. Biol Reprod 1999; 60: 1475-1482.

28. Matsui T, Manabe N, Goto $Y$, Nakayama M, Inoue $\mathbf{N}$, Nishihara S, Miyamoto $\mathbf{H}$. Changes in the expression and activity of caspase- 9 and Apaf1 in granulosa cells during follicular atresia in pig ovaries. Reproduction 2003; 126: 113-120.

29. Wada S, Manabe N, Inoue N, Nakayama $\mathbf{M}$, Matsui K, Miyamoto H. TRAIL-decoy receptor-1 disappears in granulosa cells of atretic follicles in porcine ovaries. J Reprod Dev 2002; 48: 167-173.

30. Wada S, Manabe $\mathbf{N}$, Inoue $\mathbf{N}$, Nakayama $\mathbf{M}$, Matsui K, Miyamoto H. TRAIL-decoy receptor-1 plays inhibitory role in apoptosis of granulosa cells from pig ovarian follicles. J Vet Med Sci 2002; 64: 435-439.

31. Manabe N, Goto Y, Matsuda-Minehata F, Inoue N, Maeda A, Sugimoto M, Sakamaki K, Miyano T. Regulation mechanism of selective atresia in porcine follicles: regulation of granulosa cell apoptosis during atresia. J Reprod Dev 2004; 50: 493-514. 